25 TAVI OPERATOR RADIATION DOSE COMPARED TO PCI AND ICD OPERATORS: DO WE NEED ADDITIONAL RADIATION PROTECTION FOR TRANS-CATHETER STRUCTURAL HEART INTERVENTIONS

doi:10.1136/heartinl-2011-300198.25

M Drury-Smith, A Maher, C Douglas-Hill, R Singh, M Bhabra, J Cotton, S Khogali. Heart and Lung Centre, New Cross Hospital, Wolverhampton, UK

Introduction Trans-catheter cardiac aortic valve implantation (TAVI), implantable cardiac defibrillators (ICD), and percutaneous coronary intervention (PCI), are common procedures associated with radiation exposure to the operator and the patient. Radiation dose exposure is cumulative and if above the recommended annual levels may have significant consequences for the operator. The radiation dose TAVI operators are exposed to is not widely known, but it is an important consideration in view of the increasing volume of procedures and the potential risks of over-exposure. Our aim was to monitor and compare, radiation exposure time, dose, and individual operator dose, in TAVI, PCI and ICD

Method Ten TAVIs were performed, 6 via the trans-femoral route and 4 via the subclavian approach. Radiation protection was employed in all cases using standard lead skirts and screens. During each procedure the radiation dose exposure was monitored for each operator using ThermoLuscent Dosemeters (TLD) on the left finger (LF), right finger (RF) and forehead. The six TAVI procedures performed via the transfemoral approach used only two operators, while the subclavian approach involved three operators. The third operator was a surgeon who was nearest to the $\mathrm{x}$-ray images. Radiation exposure doses were also collected from ICD and PCI operators during the same period, using the same type of TLDs on LF and RF. Operator specific radiation doses were obtained from a central RRPPS Approved Dosimetry Service. PCI was considered a standard trans-catheter procedure. TAVI and ICD operator doses were compared to the mean standardised PCI operator dose. Results The mean exposure times and doses for the different types of trans-catheter procedures performed are detailed in the tables below. Despite the use of standard radiation protection measures, the mean dose to operators undertaking TAVI was 6 times higher than the trans-femoral PCI operator $(p=0.008)$. The mean radiation exposure time of TAVI was seven times more than PCI. Although subclavian TAVI and ICD procedures were expected to be comparable with respect to operator dose, subclavian TAVI operators have an unexpectedly higher dose $(\mathrm{p}=0.03)$.

Conclusions Overall TAVI operators are exposed to significantly higher radiation doses compared to PCI and ICD operators. Additional radiation protection for TAVI operators is strongly advocated. We are currently evaluating the impact of using a RADPAD as additional protection during TAVI procedures.

Abstract 25 Table 1

\begin{tabular}{lcllr}
\hline Variable & TAVI & ICD & PCI & p Value \\
\hline Mean exposure Time (mins) & $27.0^{*}$ & 3.26 & 3.825 & $<0.001^{*}$ \\
Mean exposure Dose & $196.25 \pm 150.96 \dagger$ & $11.03 \pm 9.01$ & $33.09 \pm 11.5$ & $0.008 \dagger$ \\
(Gy/cmq) \pm SD & & & &
\end{tabular}

${ }^{*}$ Significantly increased radiation exposure time in TAVI procedures compared to ICD and PCI. †Significantly increased radiation exposure dose in TAVI procedures compared to ICD and PCI.

Abstract 25 Table 2

\begin{tabular}{llll}
\hline & $\begin{array}{l}\text { Mean radiation dose } \\
\text { (Gy/cmq) per operator }\end{array}$ & $\mathbf{\pm S D}$ & p value \\
\hline Trans-femoral TAVI & 1.67 & 1.23 & 0.03 \\
Subclavian TAVI & 2.53 & 3.09 & 0.03 \\
ICD & 1.95 & 0.14 & 0.03 \\
$\mathrm{PCI}$ & 0.18 & & 0.36 \\
\hline
\end{tabular}

\section{THE EFFECTS OF PRE-EXISTING SIGNIFICANT CORONARY ARTERY DISEASE UPON OUTCOME AFTER TRANSCATHETER AORTIC VALVE IMPLANTATION USING THE EDWARDS BIOPROSTHESIS}

doi:10.1136/heartjnl-2011-300198.26

${ }^{1} \mathrm{M}$ Z Khawaja, ${ }^{2} \mathrm{H}$ Haran, ${ }^{1} \mathrm{I}$ Nadra, ${ }^{1} \mathrm{~K}$ Wilson, ${ }^{1} \mathrm{~L}$ Clack, ${ }^{1} \mathrm{~K}$ Macgillivray, ${ }^{1} \mathrm{~J}$ Hancock, ${ }^{1} \mathrm{C}$ Young, ${ }^{1} \mathrm{~V}$ Bapat, ${ }^{1} \mathrm{M}$ Thomas, ${ }^{1} \mathrm{~S}$ Redwood. ${ }^{1}$ Guy's \& St. Thomas' Hospitals NHS Foundation Trust, London, UK; ${ }^{2}$ King's College School Of Medicine \& Dentristry, London, UK

Introduction Patients undergoing surgical aortic valve replacement (sAVR) routinely undergo simultaneous coronary artery bypass grafting $(\mathrm{CABG})$ for significant coronary artery disease (CAD) due to adverse prognostic impact. While manufacturers advise percutaneous intervention (PCI) of significant $\mathrm{CAD}$ prior to transcatheter aortic valve implantation (TAVI) there is considerable variation among operators.

Methods We performed a retrospective analysis of 168 patients who underwent TAVI using the Edwards bioprosthesis from March 2008 to October 2010 at St. Thomas Hospital, London. They were divided into two groups according to the results of the pre-TAVI coronary angiogram: (Group 1) patients with $\geq 1$ coronary stenosis of $\geq 70 \%$ severity and those without (Group 2). The end-point was all-cause mortality. Results In total, 70 patients $(41.7 \%)$ had significant CAD prior to TAVI, with $10(6.0 \%)$ undergoing PCI prior to their procedure. There were no significant differences in either the baseline characteristics or access approach between the two groups (Abstract 26 tables 1 and 2). At a mean follow-up of $335 \pm 277$ days (mean $\pm S D$ ), the overall mortality was $22.6 \%$; Group 1 mortality was $30 \%$ and in group 2 was $17.3 \%(p=0.124)$ (see Abstract 26 figure 1) There was no difference seen in the length of stay in the intensive care unit ( $2.7 \pm 6.2$ vs $4.1 \pm 14.9$ days, $p=0.462)$ nor in the number of days to discharge (12.6 \pm 10.1 vs $12.8 \pm 13, \mathrm{p}=0.928)$. Among those patients who underwent PCI in Group 1, 8 had single vessel intervention and 2 had PCI to 2 vessels. The target vessels were left main stem (LMS) $(n=2)$, proximal left anterior descending artery (LAD) $(n=5)$, circumflex $(n=1)$, right coronary artery (RCA) $(n=2)$, saphenous vein graft (SVG) to LAD $(n=1)$ and SVG to circumflex $(n=1)$. Mortality in this sub-group was not significantly different from the CAD patients who did not receive PCI ( $50 \%$ vs $26.7 \%, \mathrm{p}=0.272$ ).

\section{Abstract 26 Table 1}

\begin{tabular}{llll}
\hline & $\begin{array}{l}\text { Group 1 Significant } \\
\text { CAD (n=70) }\end{array}$ & $\begin{array}{l}\text { Group 2 No significant } \\
\text { CAD (n=98) }\end{array}$ & p Value \\
\hline Age (years \pm SD) & $83.7 \pm 7.5$ & $81.7 \pm 8.5$ & 0.112 \\
Diabetes Mellitus & $16(22.9)$ & $27(27.6 \%)$ & 0.492 \\
Cerebrovascular disease & $11(15.7 \%)$ & $17(17.3 \%)$ & 0.780 \\
Peripheral vascular disease & $15(21.4 \%)$ & $12(12.2 \%)$ & 0.110 \\
Glomerular filtration rate & $48.4 \pm 27.9$ & $46.8 \pm 23.1$ & 0.685 \\
Logistic Euroscore $(\% \pm S D)$ & $23.5 \pm 12.9$ & $21.5 \pm 16.2$ & 0.399 \\
LV ejection fraction $(\% \pm S D)$ & $48.8 \pm 11.3$ & $47.9 \pm 12.4$ & 0.658 \\
Aortic valve area (cm $\left.{ }^{2} \pm S D\right)$ & $0.63 \pm 0.20$ & $0.67 \pm 0.22$ & 0.219 \\
Previous CABG & $18(25.7 \%)$ & $27(27.6 \%)$ & 0.791 \\
Previous PCI & $16(22.9 \%)$ & $12(12.2 \%)$ & 0.070 \\
\hline
\end{tabular}

Abstract 26 Table 2

\begin{tabular}{llll}
\hline & $\begin{array}{l}\text { Group 1 Significant } \\
\text { CAD }(\mathbf{n}=\mathbf{7 0})\end{array}$ & $\begin{array}{l}\text { Group 2 No significant } \\
\text { CAD }(\mathbf{n}=\mathbf{9 8})\end{array}$ & p value \\
\hline Transfemoral & $44(44.9 \%)$ & $29(41.4 \%)$ & 0.778 \\
Transapical & $47(48.0 \%)$ & $37(52.9 \%)$ & \\
Transaortic & $7(7.1 \%)$ & $4(5.7 \%)$ & \\
\hline
\end{tabular}

Conclusion The presence of significant $\mathrm{CAD}$ had no significant impact upon the all-cause mortality of patients after TAVI in our 